\title{
Long-term field studies of old-growth forests on Changbai Mountain in Northeast China
}

\author{
Guofan Shao
}

Received: 19 May 2011 / Accepted: 19 May 2011 / Published online: 21 July 2011

(C) INRA and Springer Science+Business Media B.V. 2011

Changbai Mountain (Changbaishan or Changbai Shan in Chinese, Mount Baekdu in North Korean or Paektu-san in South Korean) lies along the border between China and North Korea and is the highest mountain in the eastern Eurasian Continent. Changbai Mountain is well known for its contiguous biodiversity-rich intact terrestrial ecosystems, including Korean pine-broadleaved mixed forest (700$1,100 \mathrm{~m})$, coniferous forest (1,100-1,700 m), Erman birch forest (1,700-2,000 m), and tundra (2,000-2600 m; Fig. 1). In the late $1950 \mathrm{~s}$, these ecosystems were systematically investigated by Prof. Zhan Wang, who was among the first generation of forest ecologists in China (Shao et al. 2000). Soon after the Cultural Revolution in the 1970s, Prof. Wang proposed the establishment of the Changbai Mountain Research Station of Forest Ecosystems (CMRSFE) and his proposal was approved by the Chinese Academy of Sciences (CAS) in 1979. CMRSFE was accepted into the United Nations Educational, Scientific and Cultural Organization's Man and the Biosphere program in 1980. With participating members including several research institutions and universities/colleges, CMRSFE has played a dominant role in forest research on Changbai Mountain.

The themes of forest ecosystem research at CMRSFE initially focused on the structure, function, and productivity of old-growth forests on Changbai Mountain. The major research objective in the initial stage from 1979 to 1982 was to collect basic information for the construction of databases on plants, animals, microorganisms, soil, meteorology, and hydrology on Changbai Mountain. In 1983-1986, CMRSFE's research objective was focused on elucidating ecological

G. Shao $(\bowtie)$

Department of Forestry and Natural Resources, Purdue University, West Lafayette, IN 47907, USA

e-mail: shao@purdue.edu principles underlying mixed forest dynamics and their applications in forest ecosystem management. Most of early research findings at CMRSFE centered on accumulating baseline information on biodiversity and forest ecosystem types, estimating biomass and productivity of forest ecosystems, spatial variations in forest composition and structure, and meteorological and hydrological characteristics of the area. Research findings were published mainly in the seven volumes of CMRSFE's Forest Ecosystem Research Bulletin from 1980 to 1994. The Symposium on Temperate Forest Ecosystem Management and Environmental Protection held at Changbai Mountain in 1986 served to promote international cooperative forest research at CMRSFE. Collaborative research projects were formally conducted involving Chinese forest ecologists and scientists from Germany, the UK, and the USA. This represented the beginning of international cooperation on forest research at CMRSFE between 1988 and 1991.

The initial research projects at CMRSFE were earned the second prize of Science and Technology Progress Award given by CAS in 1986. CMRSFE was approved as an Opened Research Station of CAS in 1989, as a key research station of the Chinese Ecosystem Research Network within the CAS in 1992, and as a node of International Long-Term Ecological Research in 1993. The strategy of long-term forest ecosystem research on Changbai Mountain included periodic in situ observations in forests, remote sensing at multiple resolutions, computer simulations of forest dynamics, and controlled experiments and observations. However, scientists from CMRSFE did not publish papers on Changbai forests in international journals until the early 1990s. The first five publications in the journals indexed in Thomson Reuter's Journal Citation Reports (or ISI journals) included Zhau and Zhau (1991) on nature reserve management, Barnes et al. (1992) on the structure and composition of 
Fig. 1 A view of Changbai Mountain from the western (Chinese) side (left photo by Quan Jiang) and the four ascending vegetation zones on the Mountain (right photos)

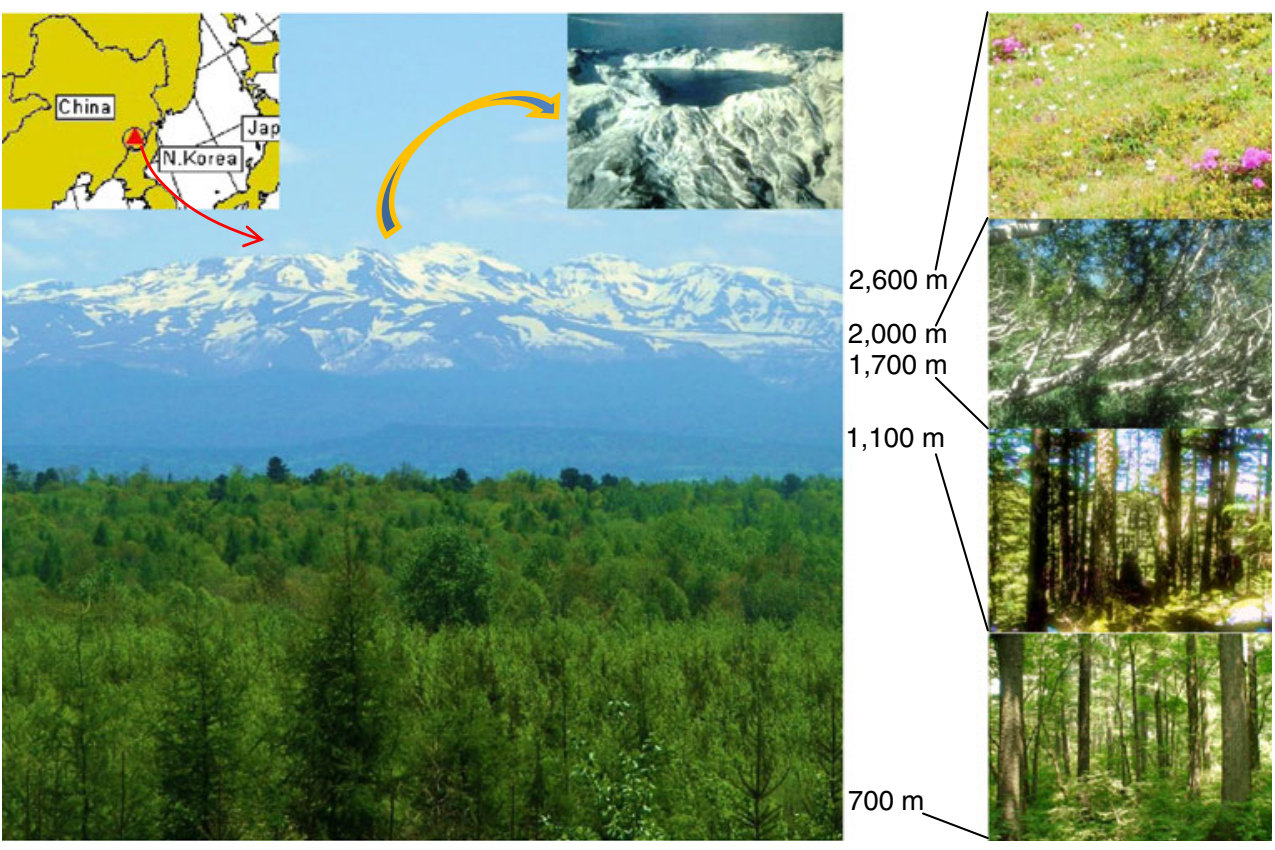

the mixed forest, Geng et al. (1993) on leaf litter decay and nitrogen dynamics, Shao et al. (1994) on forest dynamic simulations with a gap model, and Shao et al. (1996) on forest cover mapping with remote sensing data. These pioneer works from CMRSFE laid the foundation for intensified efforts in forest research on Changbai Mountain over the past two decades. To date, more than 100 research papers on Changbai Mountain forests have been published in ISI journals. At the same time, Tang et al. (2010) suggest that the understanding of forest ecosystems on Changbai Mountain needs to be improved with additional field-level, mountain-scale efforts.

As CMRSFE continued to evolve, other institutional support and funding mechanisms have become available for promoting forest research on Changbai Mountain. For instance, the Jilin Changbai Mountain Academy of Sciences at Changbai Mountain has devoted much attention to nature reserve management, biodiversity protection, and species cultivation. China's Ministry of Science and Technology has strongly supported strongly the study of sustainable forest conservation and rational forest management and use on Changbai Mountain. CAS has recently supported multidisciplinary research for developing a better understanding of forest $\mathrm{N}$ and $\mathrm{C}$ budgets and cycling on Changbai Mountain. And China's Natural Science Foundation has funded forest ecological and forestry research projects on Changbai Mountain.

This special issue contains papers written primarily by researchers who have been engaged in continuing efforts in field data collection and analysis on Changbai Mountain between 1980 and 2010. Each paper presents results of long-term forest ecosystem research projects on Changbai
Mountain and the authors are among the most recognized scientists from several research institutions that have made continuous contributions to forest research on Changbai Mountain. This special issue tends to cover broad disciplines/ approaches ranging from forest ecology to land use science, from ground observation to remote sensing/modeling, and from descriptive to analytical analysis.

Dai et al. (2011) investigated changes in forest structure and tree species composition, as well as population dynamics of the dominant tree species for two old-growth forests on Changbai Mountain from 1981 to 2010. They found that while stem density of the broad-leaved coniferous mixed forest at $740 \mathrm{~m}$ above sea level (asl) displayed almost no change, the total basal area increased from 36.2 to $46.5 \mathrm{~m}^{2} \mathrm{ha}^{-1}$. The coniferous forest at $1,680 \mathrm{~m}$ asl displayed structural changes in the form of a significant decrease in both stem density and total basal area over the study period. However, no changes in tree species composition in the two forests were observed despite the presence of wind disturbance.

Liang et al. (2011) examined whether field observations from a limited number of plots are reliable in predicting forest landscape change under climate warming. They found that for species whose distribution changes occur mainly within the same elevation zone as the experimental plots are located, plot observations may capture the changes for the entire elevation zone. In contrast, for species that span multiple elevation zones or migrate from one elevation zone to another under warming climate, plot observations are not reliable in predicting landscape level change.

Piao et al. (2011) monitored the effects of pine seed harvesting on populations of Korean pine, mammalian 
granivores and predators between 2000 and 2009 both within and outside of the nature reserve on Changbai Mountain. They found that human harvesting of pine cones was associated with declines in pine seed production and quality, pine regeneration, and populations of several wildlife species. The nature reserve generally harbored greater wildlife populations than were found outside of its boundaries. Enactment of restrictions on pine seed harvesting in 2006 led to rebounds in wildlife populations. However, seed harvest restrictions failed to diminish damage to trees by humans or seeds by insect pests, and regeneration of pine did not rebound.

Yu et al. (2011) used a dendroecological technique to examine the relationships between climate variations and radial growth of six dominant tree species on seven sites at different elevations on Changbai Mountain. They found that species differences were more important than altitudinal differences in influencing species site-specific radial growth. The results suggest that the distribution areas of dominant tree species on Changbai Mountain will shift upward, but growth of Korean pine will not decline at its lower distribution limit nor eventually disappear from forest communities in those areas under warming climate scenarios.

Zhao et al. (2011) examined deforestation processes from 1977 to 2007 for areas under the jurisdiction of two forestry enterprises - the Baihe and Lushuihe Forestry Bureaus - whose socioeconomic environments vary due to differences in their proximity to the Changbai Mountain Biosphere Reserve, which attracts hundreds of thousands of tourists each year. The Baihe Bureau, whose income was derived from both forestry and tourism, experienced more severe deforestation than did the Lushuihe Bureau whose revenue came primarily from forest products. This suggests that booming tourism in the Baihe area did not help lessen pressures on forest resources, but rather contributed to increased fragmentation of forest landscapes on Changbai Mountain.

Zhou et al. (2011a) used data from permanent plots measured periodically in 1981 and 2010 to quantify carbon densities for mixed, coniferous, and Erman birch oldgrowth forests on Changbai Mountain. Carbon density increased from 233 to $317 \mathrm{tC} \mathrm{ha}^{-1}$ for the mixed forest, from 298 to $327 \mathrm{tC} \mathrm{ha}^{-1}$ for the coniferous forest, and from 226 to $281 \mathrm{tC} \mathrm{ha}^{-1}$ for the Erman birch forest. The increases in carbon density associated with wind damages that the old-growth forests were resilient to disturbances and are stable carbon sinks under changes in climate.

Zhou et al. (2011b) compared the effects of freezingthawing cycles on $\mathrm{N}$ mineralization among soils in four vegetation zones on Changbai Mountain. They found that inorganic $\mathrm{N}$ in the soils increased while $\mathrm{N}$ mineralization rate decreased with an increase in the frequency of freezing-thawing cycles. In addition, a higher soil water content enhanced soil $\mathrm{N}$ mineralization. This indicates that freezing-thawing of the soils in the spring season is relatively effective in contributing to soil $\mathrm{N}$ mineralization.

\section{References}

Barnes BV, Xu ZB, Zhao SD (1992) Forest ecosystems in an oldgrowth pine-mixed hardwood forest of the Changbai Shan preserve in northeastern China. Can J For Res 22:144-160

Dai LM, Qi L, Su DK, Wang QW, Yu DP, Wang Y, Ye YJ, Jiang SW, Zhao W (2011) Changes in forest structure and composition on Changbai Mountain in Northeast China. Ann For Sci. doi:10.1007/s13595-011-0095-x

Geng XY, Pastor J, Dewey B (1993) Decay and nitrogen dynamics of litter from disjunct, congeneric tree species in old-growth stands in northeastern China and Wisconsin. Can J Bot 71:693699

Liang Y, He HS, Bu RC, Hu YM, Shao GF (2011) Are plot data effective for landscape prediction? A simulation study of tree species response to climate warming under varying environmental heterogeneity. Ann For Sci. doi:10.1007/s13595-011-0096-9

Piao ZJ, Tang LN, Swihart RK, Wang SX (2011) Human-wildlife competition for Korean pine seeds: vertebrate responses and implications for mixed forests on Changbai Mountain, China. Ann For Sci. doi:10.1007/s13595-011-0097-8

Shao GF, Schall P, Weishampel JF (1994) Dynamic simulations of mixed broadleaved-Pinus koraiensis forests in the Changbaishan Biosphere Reserve of China. For Eco Manage 70:169-181

Shao GF, Zhao G, Zhao SD, Shugart HH, Wang SX, Schaller J (1996) Forest cover types derived from Landsat TM imagery for Changbai Mountain Area of China. Can J For Res 26:206216

Shao GF, Liu QJ, Qian H, Chen JQ, Ma JS, Tan ZX (2000) Wang Zhan (1911-2000). Taxon 49:593-601

Tang LN, Shao GF, Piao ZJ, Dai LM, Jenkins MA, Wang SX, Wu G, Wu JG, Zhao JZ (2010) Forest degradation deepens around and within protected areas in East Asia. Biol Conserv 143:12951298

Yu DP, Wang QW, Wang Y, Zhou WM, Ding H, Fang XM, Jiang SW, Dai LM (2011) Climatic effects on radial growth of major tree species on Changbai Mountain. Ann For Sci. doi:10.1007/ s13595-011-0098-7

Zhao JZ, Li Y, Wang DY, Xu D (2011) Tourism-induced deforestation outside Changbai Mountain Biosphere Reserve, northeast China. Ann For Sci. doi:10.1007/s13595-011-0099-6

Zhau SD, Zhau G (1991) Management of Changbai Mountain Biosphere Reserve-the present conditions, problems, and perspectives. Mt Res Dev 11:168-169

Zhou L, Dai LM, Wang SX, Huang XT, Wang XC, Qi L, Wang QW, Li GW, Wei YW (2011a) Changes in carbon density for three oldgrowth forests on Changbai Mountain, Northeast China: 19812010. Ann For Sci. doi:10.1007/s13595-011-0101-3

Zhou WM, Chen H, Zhou L, Lewis BJ, Ye YJ, Tian J, Li GW, Dai LM (2011b) Effect of freezing-thawing on nitrogen mineralization in vegetation soils of four landscape zones of Changbai Mountain. Ann For Sci. doi:10.1007/s13595-011-0100-4 